\title{
INVENTÁRIO DE HISTÓRIAS DE LEITURA: RECURSO METODOLÓGICO PARA A PRÁTICA DOCENTE
}

\author{
INVENTORY OF STORIES READING: METHODOLOGICAL RESOURCE FOR \\ TEACHING PRACTICE
}

Recebido: 31/10/2020 Aprovado: 16/11/2020 Publicado: 10/01/2021

DOI: $10.18817 /$ rlj.v4i02.2406

\author{
Marinalva Aguiar Teixeira Rocha ${ }^{1}$ \\ Orcid ID: https://orcid.org/0000-0002-2712-3671 \\ Dulce Helena Teixeira dos Santos ${ }^{2}$ \\ Orcid ID: https://orcid.org/0000-0002-8037-7232
}

\begin{abstract}
Resumo: O presente artigo foi construído a partir do relato de histórias de leitura vivenciadas pelos alunos iniciantes do Curso de Letras do CESC/UEMA, quando dos primeiros contatos com o texto escrito. O objetivo da pesquisa foi refletir, a partir das narrativas [por eles produzidas], como as memórias de leitura da infância podem contribuir, de forma significativa, com o processo de formação profissional, quando do exercício da docência. As ocorrências memorialísticas são constituídas por várias recordações guardadas ao longo dos anos e que podem ser trazidas para o presente, a fim de reativar a memória desses sujeitos. A ideia da produção de histórias de leitura também se pautou em identificar, ao longo do exercício de rememoração, o processo que consolidou a prática de leitura de cada um. Para fundamentar as discussões a respeito de formação de leitor, buscou-se aporte teórico em Lacerda (2009), Rocha (2014; Maia (2020); Cosson (2014), entre outros.
\end{abstract}

Palavras-chave: Formação de Leitor. Memória de leitura. Prática docente.

Abstract: This article was built from the story of reading stories experienced by beginning students of the Letters Course at CESC / UEMA, when they first came into contact with the written text. The objective of the research was to reflect, from the narratives [produced by them], how the childhood reading memories can contribute, in a significant way, with the process of formation of the professional of letters, when teaching. The memorialistic events are constituted by several memories kept over the years and that can be brought to the present, in order to reactivate the memory of these subjects. The idea of producing stories was also based on identifying, throughout the remembrance exercise, the process that consolidated the reading practice of each one. To support the discussions regarding the reader formation, theoretical support was sought in Lacerda (2009), Rocha (2014; Maia (2020); Cosson (2014), among others.

Keywords: Reader training. Reading memory. Teaching practice.

\section{Considerações iniciais}

O verbo ler não suporta o imperativo.

(Daniel Pennac, 2011, p.13)

\footnotetext{
${ }^{1}$ Professora Adjunta do Departamento de Letras do Centro de Estudos Superiores de Caxias da Universidade Estadual do Maranhão. Graduada em Letras (UEMA). Especialista em Língua Portuguesa (PUC-MG). Mestre em Letras (UERJ), com área de concentração em Língua Portuguesa. Doutora em História (UNISINOS), área de concentração em Estudos Históricos Latino-Americanos. Email:marinalvaat@hotmail.com

2 Professora Substituta do Departamento de Educação do Centro de Estudos Superiores de Caxias da Universidade Estadual do Maranhão. Atua no Ensino Médio como Coordenadora Pedagógica. Graduada em Pedagogia (UEMA). Especialista em Gestão e Supervisão Escolar (UEMA). Mestranda em Educação (UNISINOS).E-mail: dulce_helenas@hotmail.com
} 
A escrita da história de leitura constitui um recurso de efetiva importância para a preservação da memória, uma vez que esse meio serve para inventariar os acontecimentos de um tempo e para resguardar as lembranças desse tempo, tanto no âmbito individual como coletivo. A memória é ativa, o ato de recordar é um processo dinâmico que está sempre retornando ao passado para manter vivas as lembranças. Dessa forma, a construção das histórias de leitura pode ser reconhecida como um importante registro das práticas leitoras as quais os sujeitos realizam ao longo dos tempos. Para Halbwachs $(2013,93)$, "a lembrança é uma imagem introduzida em outras imagens, uma imagem genérica transportada ao passado".

Pretendemos, neste trabalho, registrar diversas experiências de leitura vivenciadas por acadêmicos, especificamente, em suas infâncias. O que interessa aos propósitos desse trabalho é mostrar como cada sujeito se relacionou com o objeto livro, quais ações/pessoas influenciaram na sua formação de leitor, isto é, quais memórias de leitor infantil interferiram no efetivo exercício de sua prática acadêmica, enquanto estudante de Letras. Também é fundamental indagar a maneira pela qual cada sujeito se inseriu no universo da leitura, como cada um relata sua experiência. Para tanto, buscamos analisar a história de leitura de estudantes iniciantes do Curso de Letras do Centro de Estudos superiores de Caxias, a partir dos relatos apresentados em uma atividade proposta durante a disciplina Leitura e Produção de Texto, momento em que Ihes foi solicitado o registro de suas memórias de leitura.

Entendemos que o valor da pesquisa se ancora no anseio de observarmos como o aluno iniciante percebe o seu processo de aprendizagem de leitura, sua concepção sobre as possibilidades que a leitura pode proporcionar às pessoas, a forma como cada um passou a fazer parte do mundo da leitura, a fim de conduzi-los a perceber que, para a sua futura atuação profissional, cada história de leitura tem fundamental importância, até mesmo para perceber o que não foi favorável para a sua formação e, com essa constatação, quando do exercício da profissão, buscar novos caminhos.

\section{Experiências de Leitura: Recurso metodológico para prática docente}


Em lugar de deixar a inteligência do texto falar por nossa boca, nos remetemos à nossa própria inteligência e falamos do texto. Não somos os emissários do livro, mas os guardiões juramentados de um templo, cujas maravilhas exaltamos com as palavras que lhes encerram as portas: É preciso ler, é preciso ler! (PENNAC, 2011, p. 85).

\title{
A seguir, apresentamos algumas narrativas as quais revelam como
} ocorreram os processos de formação dos leitores pesquisados. Relatos que apontam, muitas vezes, aspectos que serviram para tornar positivo o caminho trilhado por esses sujeitos, porque lhes abriram portas para se tornarem leitores efetivos, capazes de fazer do livro objeto de prazer. Para outros, as memórias sobre a relação com 0 ato de ler registram uma prática de momentos que se tornaram angustiantes, na medida em que muitas ações realizadas durante o processo de leitura e intermediadas por professores ou familiares provocaram medo, receio de não aprender, não saber, não entender o lido e, portanto, resultou em desânimo. Para Cunha e Capellini,

A memória é definida como a capacidade de fixar, conservar e reproduzir, sob a forma de lembranças, impressões e sensações obtidas ou vividas pelo indivíduo anteriormente. Por meio desta capacidade, é possível adquirir, reter e recuperar informações de forma consciente ou inconsciente, quando necessário. (CUNHA E CAPELLINI, 2009, p. 57).

A memória de que falam Cunha e Capellini pode ser evidenciada nas falas [dos sujeitos entrevistados] apontadas abaixo:

\begin{abstract}
Das vagas lembranças de infância, tenho a imagem de meu pai me entregando o livro que minha mãe costumava fazer a leitura para mim, depois mostrava o texto que eu precisava ler e depois anotar no caderno algo sobre a leitura, o que eu entendia [...]. Partindo um pouco a frente dessa memória, recordo-me ainda de um livro infantil que lia bastante quando era criança, o título exato me falha no momento, mas se tratava de uma formiga que ficava presa na neve e pedia ajuda para todos os personagens que passavam por ela, era uma história narrada e ilustrada com belos desenhos, foi de fato um dos primeiros contatos com a leitura que tive em minha vida, e por ser uma história ilustrada, talvez tenha contribuído muito para me interessar por histórias em quadrinhos, algo que foi bastante importante para a minha entrada no mundo da leitura e ainda é com entusiasmo que cultivo até hoje.

Eu sempre tive um interesse bem maior pelos desenhos do que pela leitura da palavra escrita, deve-se ao fato de que eu desenhava desde quando era bem pequeno. Isso se deve ao fato de ter aprendido a desenhar antes de escrever ou ler, o que é natural. Pensava que talvez esse fato tivesse atrapalhado um pouco o meu desempenho com a leitura. Pois, nos livros, eu sempre prestava mais atenção aos desenhos que ilustravam as páginas dos livros da escola do que aos textos. Entretanto, hoje, percebo que decifrar as imagens também é parte do processo de leitura. (Y.S.M);
\end{abstract}

Minha história de leitura começa antes da alfabetização. Meus pais sempre leram livros infantis para mim, lembro especialmente de O Patinho Feio e Os Três Porquinhos, obras que me encantavam bastante, fazendo minha mãe lê-las repetidas vezes. No percurso da alfabetização, 
meu avô paterno foi meu guia, com a sua ajuda, do jardim de infância fui direto para o $1^{\circ}$ ano, pois aprendi a ler aos 5 anos. Meu avô é a minha mais clara lembrança de incentivo aos estudos e à leitura [...]. (R.M.S);

[...] Minha avó materna desenvolveu, de maneira extraordinária, o papel de pedagoga, durante toda a minha formação. Com minha avó, tive o maior incentivo aos estudos e, sobretudo à leitura. (B.B.);

Nascida de uma família sem leitura, em que bisavós, avós e mãe possuíam pouca escolaridade ou nenhuma escolarização, algo despertava em mim curiosidade: o meu bisavô materno (pai do meu avô materno) era um leitor e tanto. Acho que ele foi um grande incentivo. (B.P.)

Fonte: Arquivo das pesquisadoras

As narrativas acima descritas mostram com clareza a importância da família no desempenho das práticas leitoras dos filhos [“... tenho a imagem de meu pai me entregando o livro que minha mãe costumava fazer a leitura para mim"/ "No percurso da alfabetização, meu avô paterno foi meu guia, com a sua ajuda, do jardim de infância fui direto para o $1^{\circ}$ ano, pois aprendi a ler aos 5 anos"/ "Com minha avó, tive o maior incentivo aos estudos e, sobretudo à leitura"]. O desenvolvimento dessa habilidade requer um comprometimento familiar que se coadune com o que a escola propõe, ou seja, a necessidade do envolvimento de todos quando se quer levar o sujeito a ser leitor proficiente.

Essa fase de aprendizagem é fundamental para a criança começar a se interessar pela leitura, fato que, pode ser decisivo para a aquisição de competência significativa para a formação integral do sujeito. Essas memórias trazem para discussão elementos que devem ser considerados quando do incentivo ao ato de ler como, por exemplo, ler para o outro, ler para o filho, porque "leitura e afeto com frequência fazem par" (LACERDA, 2009, p. 20), afirma ainda a pesquisadora que

O livro é parte do conforto que acompanha no colo familiar, ao experimentar, por meio da voz afetuosa e dos encantos narrativos, emoções que tocam de maneira próxima. A associação entre livro e pessoas queridas confere ao objeto a aura de confiança, necessária à relação pródiga com a subjetividade. (LACERDA, 2009, p. 20).

Outro aspecto a ser observado na memória de leitura do aluno diz respeito ao atrelamento do ato de ler ao ato de escrever [“... depois anotar no caderno algo sobre a leitura, o que eu entendia..."], relação vista de forma positiva, desde que seja um processo realizado sem cobrança, isto porque, não havendo preocupação com o certo/errado, aumenta-se a possibilidade de o aluno escrever de forma espontânea e 
prazerosa. Nesse sentido, é importante trazer para reflexão as ideias de Pennac (2011, p. 110) ao afirmar que "não pedir nada em troca. Absolutamente nada" seria uma condição para o sujeito adentrar no universo da leitura, se afeiçoar, não se aproveitando do momento para subtrair dali uma nota. Dessa forma, é importante ainda amparar tal discussão nas ideias de Lacerda ao ressaltar que

\begin{abstract}
Escrita e leitura são aquisições culturais que, à semelhança da postura vertical, se instauram por efeito da convivência. A mediação de um adulto é fundamental para o exercício dessas práticas na vida de uma criança, práticas cuja realização exige ademais a presença deste objeto refinado e primordial - o livro. (LACERDA, 2009, p. 20).
\end{abstract}

Tal processo dialógico [leitura/escrita] desenvolve atitudes positivas no sujeito aprendiz, visto que o contato da criança com a escrita possibilita expandir o universo vocabular, a criatividade, dota-a de competência expressiva que, ao ser mediada pela literatura, pode despertar o prazer de ler, por meio do contato com o aspecto lúdico evidenciado no texto infantil. O domínio da língua escrita só é possível quando o aluno emerge no mundo da leitura, de tal modo que podemos afirmar que "o ato de ler é incompleto sem o ato de escrever. Um não pode existir sem o outro. Ler e escrever não apenas palavras, mas ler e escrever a vida, a história" (GADOTTI, 1995, p. 93).

No primeiro relato, pode-se perceber, ainda, que ilustrações são recursos essenciais para atrair a atenção das crianças e facilitar as suas escolhas ["Eu sempre tive um interesse bem maior pelos desenhos do que pela leitura da palavra escrita" / "hoje, percebo que decifrar as imagens também é parte do processo de leitura"]. Essa fala deixa transparecer que o leitor percebeu que compreender o que a imagem evidencia também é leitura, é uma forma de decifrar palavras escondidas, visto que, nas palavras de Pesavento (2008, p, 109), "imagens contêm discursos e os textos remetem a imagens, visuais e mentais. Imagens dão a ver e dão a ler".

O relato a seguir evidencia a importância da instituição escolar no desempenho das habilidades do estudante. Nele, percebe-se que para levar o sujeito a interessar-se pelo universo da leitura é necessário iniciar o caminho desde a mais tenra idade. Nesse percurso, a educação escolar se reveste de um papel fundamental na vida da criança, considerando que a escola é um espaço que deve chamar a atenção da sociedade pela sua proposta pedagógica, espaço que desenvolva projetos adequados à comunidade estudantil, assim como lugar que tem 
ou deveria ter profissionais preparados para trabalhar, principalmente, com o intuito de formar leitores.

Nesse sentido, o trecho abaixo, extraído de um dos relatos sobre história de leitura, explicita o sentimento do aluno em relação ao papel da escola:

A escola foi fundamental no início da minha caminhada no mundo da leitura. Conheci sereias, mundos encantados, tesouros escondidos dentro da biblioteca da minha escola. Lembrome de como todos ficávamos felizes quando a professora nos levava para lá. Li contos de fada, lendas, desenhei histórias e amava gibis. (N.O.A.)

Fonte: Arquivo das pesquisadoras

É no âmbito escolar que a criança inicia, quase sempre, seus primeiros contatos com o texto escrito. Portanto, é fundamental que seja colocada à disposição do aluno, desde as primeiras séries, leituras de teor literário, visto que a literatura, além de encantar e atrair o leitor, sobretudo, pelo seu caráter expressivo, ela colabora para que o sujeito desenvolva seu potencial linguístico. Para Cosson,

[...] na escola, a leitura literária tem a função de nos ajudar a ler melhor, não apenas porque possibilita a criação do hábito de leitura ou porque seja prazerosa, mas sim, e sobretudo, porque nos oferece, como nenhum outro tipo de leitura faz, os instrumentos necessários para conhecer e articular com proficiência o mundo feito linguagem. (COSSON, 2014, p.30).

Dessa forma, para a escola alcançar o êxito revelado por Cosson, é essencial a existência de professores bem formados e com objetivos bem definidos, "a fim de propiciar o encontro dos alunos com textos que não conhecem e não seriam capazes de buscar por si mesmos [...], bem como suscitar o prazer de ler." (ROCHA, 2014, p. 22). Toda instituição escolar, sobretudo, aquelas que trabalham com as séries iniciais do Ensino Fundamental, precisam disponibilizar no acervo obras de diversos autores da literatura infantil e juvenil, assim como outros textos, como meio de propiciar o acesso dos estudantes à arte de ler. Corroborando com o exposto, Martins (2019) adverte que "é função da escola desenvolver nos alunos a habilidade da leitura e, para isso, "é preciso que o professor escolha livros que tenham qualidade literária e que transforme as leituras feitas em sala de aula em momentos de incentivo" (MAIA, 2020, p. 53).

Vale dizer, portanto, que a atitude da professora de levar seus alunos para a biblioteca parece ter promovido um diferencial na vida da aluna ["Lembro-me de como todos ficávamos felizes quando a professora nos levava para lá. Li contos de 
fada, lendas, desenhei histórias e amava gibis"], mas é importante perceber que esse diferencial somente é possível quando se tem um propósito, isto é, quando o professor tem objetivos claros para cada ação planejada. A esse respeito afirma Oliveira (2008, p. 36) que "é fundamental que o professor esteja capacitado para usar as dinâmicas de leitura e levar o aluno para além da compreensão linear das histórias, a fim de descobrir seus múltiplos significados".

Nos dois relatos descritos a seguir, percebe-se o envolvimento da criança com a leitura sem compromisso de fazer tarefa, leitura despreocupada, sem obedecer a roteiro previamente estabelecido, o que demonstra a satisfação do aluno pela ação que desenvolve a partir do objeto que lhe foi apresentado: a revista em quadrinhos.

\footnotetext{
Ao descobrir as revistas em quadrinhos de heróis com 9 anos, descobri um mundo novo, mais amplo e mais idealizado do que realmente é. As revistas, lia-as desordenadamente, sem respeitar cronologia ou contexto, o que me importava era a emoção que passavam. (C.P.S.);

[...] Comecei a gostar de ler quando ganhei o primeiro gibi, aquelas histórias me encantavam mais do que as leituras da escola, lembro das figuras, dos personagens. Tudo ganhava sentido quando lia, mas o tempo foi passando e outras leituras surgiram, mas nenhuma igual era igual as revistinhas que eu lia. (B.P.)
}

Fonte: Arquivo das pesquisadoras

Os gibis são textos que provocam a criança para desenvolver o imaginário e a criatividade, considerando a sua estrutura gráfica, as imagens, os personagens, enfim elementos que oferecem dinamicidade ao texto e que correspondem ao interesse da criança por ser uma leitura que tem caráter de divertimento e por estar imbuída de comicidade, trazendo, muitas vezes, personagens caricaturados. As histórias em quadrinhos [HQs] são, portanto, segundo Rezende (2009, p.126), "obras ricas em simbologia - podem ser vistas como objeto de lazer, estudo e investigação. A maneira como as palavras, imagens e as formas são trabalhadas apresenta um convite à interação autor-leitor".

Dessa forma, a $\mathrm{HQ}$ pode ser tida como uma grande aliada do professor no desenvolvimento de atividades didáticas de incentivo à leitura. Tal gênero ajuda a romper com a barreira que a criança cria em relação à prática de leitura, uma vez que sua forma híbrida [palavras e imagens] de descrever/narrar histórias e personagens aproxima a criança do universo leitor. A prática de leitura se torna mais expressiva quando realizada por prazer. Nessa perspectiva, o docente, ao aproveitar a relação estabelecida pela criança com a HQ, estará trabalhando com atividades que dão sentido à leitura e que se coadunam com o universo do aluno, as 
quais exploram os mais variados signos linguísticos trazidos por esse gênero. Corroborando com o exposto, Vergueiro (2010, p. 21-22) destaca a importância da leitura de HQ no ambiente escolar, entre as quais serão evidenciadas as seguintes:

i.) Os estudantes querem ler os quadrinhos;

ii.) Palavras e imagens, juntos, ensinam de forma mais eficiente;

iii.) Existe um alto nível de informação nos quadrinhos;

iv.) As possibilidades de comunicação são enriquecidas pela familiaridade com as histórias em quadrinhos;

v.) Os quadrinhos auxiliam no desenvolvimento do hábito de leitura;

vi.) Os quadrinhos enriquecem o vocabulário dos estudantes;

vii.) O caráter elíptico da linguagem quadrinística obriga o leitor a pensar e imaginar;

viii.) Os quadrinhos têm um caráter globalizador;

ix.) Os quadrinhos podem ser utilizados em qualquer nível escolar e com qualquer tema.

Antes, eu não gostava de ler, acho que por isso eu detestava as aulas de português, achava maçante e cansativa. Sempre tinha que ler o texto do livro e responder depois as perguntas sobre a gramática e o texto, disso é que ninguém não gostava sempre a mesma coisa [...]. (E.J.S)

Fonte: Arquivo das pesquisadoras

A narrativa acima é um convite para discutir sobre a relação estabelecida entre o ensino de Língua Portuguesa e as práticas de leitura. Para muitos, a leitura passa a ser vista como atividade que deve estar, tão somente, agregada à citada disciplina. O que o aluno revela em seu texto [...eu não gostava de ler, acho que por isso eu detestava as aulas de português...] mostra claramente que, muitas vezes, a barreira que impede o estudante de se sentir atraído pela leitura se justifica pela prática de atrelar a aula de português/gramática ao ato de ler. Como se vê, esse distanciamento do aluno demonstra a ação do docente quando estabelece o vínculo entre ler e ensino de normas gramaticais, aproveitando, nesse caso, o texto para discutir exclusivamente questões relacionadas a normas do português, esquecendo de relacionar tais discussões às questões estéticas da língua, como, por exemplo, explorar a expressividade que o texto traz e não é evidenciado. Essa discussão leva a perceber o engajamento do professor com a prática do ensino tradicional, quando busca no texto um pretexto para o ensino de gramática. Para Pereira,

A inserção da leitura na escola se realiza muitas vezes de forma equivocada. A leitura não é uma atividade da língua portuguesa, assim como a compreensão, a interpretação, a redação, a gramática e os exercícios distribuídos no desdobramento da disciplina. A língua portuguesa é, sem dúvida, a essência da leitura, o que a motiva, o que the confere existência, a sua materialidade. (PEREIRA, 2011, p. 171). 
discurso de memória do discente possibilita ainda que se reflita sobre a concepção que se tem de linguagem. Na concepção que melhor se adequa, a leitura é vista como processo dialógico de interatividade, quando o leitor possa ser capaz de produzir sentido ao que leu, construir conhecimento a partir da leitura, preencher lacunas trazidas no texto, tomar de decisões e, não apenas, extrair informações nele contidas, decodificar mecanicamente o que já está posto, como narra o aluno, cuja metodologia "implica uma consequência: a escola até consegue ensinar o povo a ler, porém não forma leitores" (MAIA, 2020, p. 30).

O incentivo ao ato de ler ultrapassa os limites de extração de possíveis respostas ao que foi solicitado ou à abordagem de elementos gramaticais. Para Rocha (2014, p.26), "não se deve considerar o ato de ler com o propósito de decodificação do texto escrito ou, exclusivamente, para responder a tarefas gramaticais, ação que constitui uma concepção de leitura não mais aceitável". Nesse sentido, os Parâmetros Curriculares Nacionais expressam o seguinte:

A leitura é o processo no qual o leitor realiza um trabalho ativo de compreensão e interpretação do texto, a partir de seus objetivos, de seus conhecimentos sobre o autor, de tudo o que sabe sobre a linguagem etc. Não se trata de extrair informações, decodificando letra por letra, palavra por palavra. Trata-se de uma atividade que implica estratégias de relação, participação, inferência e verificação, sem as quais não é possível proficiência. (BRASIL, 1998, p. 69).

A perspectiva de desenvolver no sujeito o prazer de ler se pauta na ideia de promover a interação entre leitor-texto, cuja ação se ampara, sobretudo, na metodologia adotada pelo docente.

A despeito do meu encantamento pela leitura, vivi um episódio que me marcou negativamente. Em um dado momento do Ensino Fundamental, uma professora me entregou um livro para que eu lesse, ainda que sem nenhum compromisso com as disciplinas da sala de aula, livro esse que hoje considero como uma exímia obra de arte, mas que naquele momento, por sua forma muito técnica de apresentar a história e por seu vocabulário arrojado acabou tornando-se maçante para mim. Após aquela leitura comecei a ver o ato de ler de uma maneira estigmatizada. Por conta da dificuldade que tive para entender aquele livro pensava que ler era algo destinado apenas a pessoas de capacidade cognitiva extremamente desenvolvida, criando, assim, uma certa aversão aos livros, vendo-os como enfadonhos objetos de tortura. (M.M.M.S)

Fonte: Arquivo das pesquisadoras

Nesse relato, percebemos que o desencanto do estudante pela leitura advém da postura da professora em relação ao encaminhamento das tarefas em 
sala de aula, do seu modus operandi. Fato que coloca o aluno em uma posição de desconforto, levando-o a ver "o ato de ler de uma maneira estigmatizada", visto que, para ele, a prática de leitura é algo atinente "apenas a pessoas de capacidade cognitiva extremamente desenvolvida". Para Pereira,

Geralmente se trata a leitura nas escolas como atividade obrigatória e/ou enfadonha. Mesmo os que gostam, às vezes, se desinteressam, se orientando apenas para a formação de "hábitos". O ato de ler deve ser prazeroso, envolvendo a possibilidade de crescimento sociocultural equilibrado, além do genuíno encantamento que proporciona. Parece oportuno se, então levarmos o aluno a perceber essa gramática da língua na prática (no texto), despertando-o para o papel da leitura em sua vida (PEREIRA, 2007, p. 31).

O depoimento desse aluno mostra que uma ação da professora marcou, de forma negativa, o seu processo de iniciação à formação enquanto leitor. Tal atitude provém da maneira tradicional de condução do processo escolar, o que seria, para ela, uma maneira de potencializar o ensino com a indicação de leitura de obra que, nas palavras do estudante, se torna maçante por "sua forma muito técnica de apresentar a história e por seu vocabulário arrojado". Para alguns, parece que "há práticas institucionalizadas de leitura, que determinam quais textos serão lidos, e quais indivíduos os lerão" (PAULINO, 2010, p.46), atitudes essas que servem para tornar os livros "objetos de tortura".

A forma de agir da professora, certamente servirá para subsidiar a prática desse aluno quando do exercício das suas funções pedagógicas, quer seja como docente em sala de aula quer seja como mediador da leitura em biblioteca escolar, evitando ocorrências dessa natureza. Diante disso, é interessante que as obras sejam selecionadas com observância aos interesses dos alunos e, sobretudo, sejam previamente lidas pelo docente a fim de, entre outros propósitos, analisar a linguagem nela expressa.

Cumpre enfatizar, ainda, que o papel da escola e do professor, para que o aluno se aproxime do ato de ler, seriam aperfeiçoar suas práticas metodológicas, assim como os instrumentos para uso dessas práticas, adotando um projeto de ensino de modo coletivo e que melhor se adeque às condições e níveis dos alunos.

A minha história de leitura iniciou no auge dos meus seis anos, quando eu andava pelas ruas e observava os letreiros e outdoors da cidade onde morava. Eram palavras nas suas variadas cores e nos maiores e menores tamanhos. (C.B.C.R.)

Fonte: Arquivo das pesquisadoras 
O acesso ao aprendizado da leitura, como também o desenvolvimento do prazer de ler tem sido um dos maiores desafios da escola. Dessa forma, a escola, instituição formal, deveria aproveitar o conhecimento prévio do aluno, o que ele adquiriu fora da escola, uma vez que a escola não pode deixar de lado as práticas de leitura que relacione o aluno aprendiz a diversos espaços sociais por ele trilhados. Trata-se de resgatar ou (res) guardar todo recurso linguístico que ele adquiriu para fazer frente ao que será ensinado e incentivado a aprender. Para Cosson (2014, p 36), "é papel do professor partir daquilo que o aluno já conhece para aquilo que ele desconhece, a fim de se proporcionar o crescimento do leitor por meio da ampliação de seus horizontes".

Como se vê, a história de leitura desse aluno é iniciada aos seis anos. O processo de aprendizagem, nesse caso, escapa aos moldes convencionais de leitura de, por exemplo, começar pelo impresso. O ato de ler, para ele, iniciou de maneira informal, em meio a descobertas de letras e palavras em letreiros e outdoors, recursos que, naturalmente, prendem a atenção de crianças, sobretudo, na idade de alfabetização. Esse relato resgata uma memória de leitura que teve início em um espaço social que não se assemelha ao da escola e nem da família, mas que contém traços que socializam saberes e seduz o aprendiz pela forma de se apresentar, visto que sua estrutura linguística produz sentido ao leitor. Forma e conteúdo se associam - letras, cores e imagens ["Eram palavras nas suas variadas cores e nos maiores e menores tamanhos".].

\section{Considerações finais}

Ao longo das análises das histórias de leituras foi possível verificar a importância de levar para sala de aula discussões promovidas pelo próprio discurso dos acadêmicos, sobretudo, dos iniciantes, cujos elementos os conduzam a perceber o quão suas experiências são fundamentais para subsidiar o trabalho docente quando passarem a exercê-lo. São práticas que propiciam refutar sobre métodos que devem ser rejeitados ou aperfeiçoados para a otimização do desempenho discente, no concernente ao processo de formação do leitor. Dessa forma, as experiências dos alunos vivenciadas na infância, ao serem trazidas para o momento atual, servem como balizador para a construção de novas estratégias para 
o futuro formador de leitor. Essas vivências também darão suporte para que o então acadêmico possa (re) significar seu processo ainda em formação.

Cabe dizer, ainda, que as narrativas dos estudantes, ao revelarem, as variadas formas que se inseriram no universo leitor [com sucesso ou não], de maneira frustrante ou satisfatória, propiciam uma discussão que se deve estabelecer sobre diversos aspectos, entre eles:

- as abordagens metodológicas de ensino [as escolhas];

- a essência da parceria da escola com a família;

- o papel da leitura no desempenho da escrita;

- a importância do conhecimento e entendimento do acadêmico sobre as concepções de leitura como elemento facilitador da prática de ensino;

- o papel do professor, o que implica na necessidade de formação contínua do profissional.

São memórias que traduzem com detalhes os modos que os alunos se inseriram no mundo da leitura e mostram meios de (re) construir seu trajeto enquanto leitor. Com base nessas narrativas foi possível perceber, ainda, o importante compromisso que a família deve ter no processo de letramento dos filhos, ainda que tenham pouca intimidade com o objeto livro, tenham baixa escolaridade [como visto em algum relato]. A dinâmica familiar [que vai desde o hábito de contar histórias, recitar versos, ler gibis] constitui um dos fatores que podem ser considerados para tornar a criança e depois o jovem mais próximo do ato de ler com prazer, o que torna o sujeito mais dinâmico e criativo nas tomadas de decisões.

\section{BIBLIOGRAFIA}

BRASIL, Secretaria de Educação Fundamental. Parâmetros Curriculares Nacionais: Língua Portuguesa. Brasília, DF, 1998.

Cunha VLO, Capellini SA. Desempenho de escolares de $1^{a}$ a $4^{\underline{a}}$ série do Ensino Fundamental nas provas de habilidades metafonológicas e de leitura - PROHMELE. Rev Soc Bras Fonoaudiol. 2009;14:56-68.

COSSON, R. Letramento literário: teoria e prática. 2. Ed. 4aㅡ reimpressão. - São Paulo: Contexto, 2014. 
GADOTTI, Moacir. O que é ler? Leitura: teoria e prática. Porto Alegre: Mercado Aberto, 1995.

HALBWACHS, Maurice. A memória coletiva. São Paulo: Centauro, 2013.

LACERDA, Nilma. Casa da Leitura: presença de uma ação: filosofia e perfil da Casa de leitura, Programa Nacional de incentivo à leitura/PROLER. 2. Ed. Rio de Janeiro: Fundação Biblioteca Nacional, 2009.

MAIA, Joseane. Literatura infanto-juvenil na formação de leitores e professores. Jundiaí (SP): Paco, 2020.

MARTINS, Milena Ribeiro. Três questões sobre formação de leitores: bibliotecas escolares, prática de leitura e fragmentação. Revista de Letras JUÇARA, CaxiasMaranhão, v.03, n.02, p.6-17, Dez. 2019.

OLIVEIRA, Maria Alexandre de. A literatura para crianças e jovens no Brasil de ontem e hoje: caminhos de ensino. São Paulo: Paulinas, 2008.

PAULINO, Graça. Das leituras ao letramento literário. Belo Horizonte: FaE/UFMG e Pelotas: EDGUFPel, 2010.

PENNAC, Daniel. Como um Romance. Tradução de Leny Werneck. 4ㄹeㄹ. Rio de Janeiro: Rocco, 2011.

PEREIRA, Maria Teresa Gonçalves. A Língua Portuguesa e a leitura: convergências no ensino e na vida. In: OLIVEIRA, leda (Org.). O que é qualidade em literatura infantil e juvenil? Com a palavra, o educador. São Paulo: DCL, 2011.

Maria Teresa Gonçalves. Proposta para um ensino prazeroso de Língua Portuguesa. In: CONGRESSO NACIONAL DE LIGUÍSTICA E FILOLOGIA, 11. 2007, Rio de Janeiro. Anais. Rio de Janeiro: CiFEFiL, 2007.

PESAVENTO, Sandra Jatahy. O mundo da imagem: território cultural. In: PESAVENTO, Sandra Jatahy; SANTOS, Nádia Maria Weber; ROSSINI, Miriam de Souza (Org.). Narrativas, imagens e práticas sociais: percurso em história cultural. Porto Alegre: Asterisco, 2008, p. 99-122.

REZENDE, Lucinea Aparecida de. Leitura e Formação de Leitores: Vivências TeóricoPráticas. Londrina: Eduel, 2009.

ROCHA, Marinalva Aguiar Teixeira. A expressividade em Ana Maria Machado e José Paulo Paes: uma proposta para motivar a leitura. Curitiba: Appris, 2014.

VERGUEIRO, Waldomiro. A linguagem dos quadrinhos: uma "alfabetização" necessária. In: RAMA, Ângela; VERGUEIRO, Waldomiro. (Orgs.). Como usar as histórias em quadrinhos na sala de aula. 4. ed. São Paulo: Contexto, 2010. 